\title{
Successful endoscopic transgastric retrieval of a plastic stent that migrated into the abdominal cavity during pancreatic fistula drainage
}

Pancreatic fistula is one of the most common complications after pancreatic surgery. Placement of a double-pigtail stent is often used as a rescue therapy [1-3]. However, often the stent migrates, which may lead to surgical intervention. We report a case in which a double-pigtail stent migrated into the abdominal cavity and was retrieved by endoscopic transgastric treatment.

A 30-year-old man who had undergone peripancreatic necrosis resection for severe acute necrotizing pancreatitis, with intraoperative placement of a surgical drain, developed pancreatic fistula 2 months later. To internalize the external drainage, via the surgical drainage channel and under CT guidance, a double-pigtail stent was placed with one pigtail within the stomach. CT scanning 3 months after stent placement showed acute pancreatitis. Digital radiography revealed that the pigtail in the stomach had migrated into the abdominal cavity, and several attempts at adjustment via the percutaneous drainage channel failed. At this point the patient was referred to our center for endoscopic treatment.

Fluoroscopy revealed the stent close to the posterior wall of the stomach ( $\triangleright$ Fig. $\mathbf{1}$ ), and no ulcer was detected in the gastric mucosa. We decided, with the patient's informed consent, to perform endoscopic transgastric retrieval of the migrated stent. First, we used a DualKnife (KD-650Q; Olympus) to partially incise the gastric wall, for a length of $1.0 \mathrm{~cm}$, which was marked under fluoroscopic guidance ( $\mathbf{F i g} . \mathbf{2}$ ). Then the migrated stent was exposed. Next, we retrieved one pigtail of the stent from the abdominal cavity using a foreign body forceps. Finally, we adjusted the position of the stent and closed the artificial ulcer with two clips (> Fig.3). Digital radiography with contrast injection showed the stent to be unobstructed ( $\vee$ Fig. 4, $\vee$ Video 1 ).

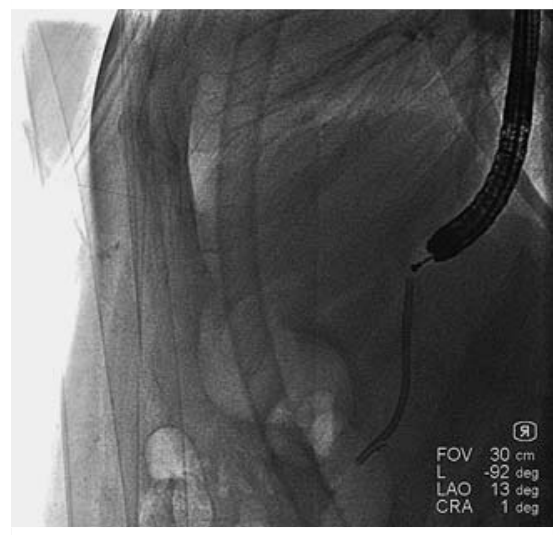

- Fig. 1 Fluoroscopy revealed the stent close to the posterior wall of the stomach.

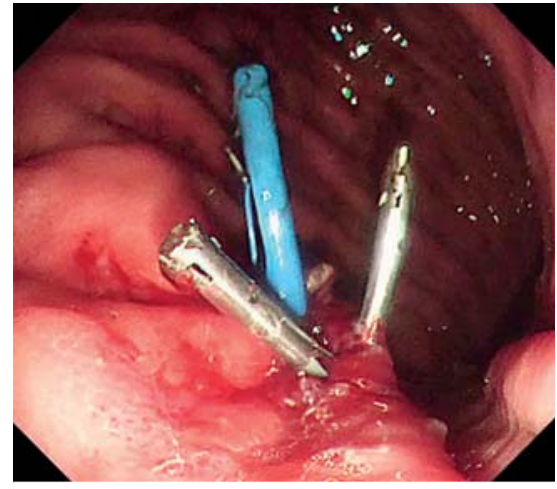

- Fig. 3 The artificial ulcer was closed with two clips.

This is the first report of successful endoscopic transgastric retrieval of a plastic stent that had migrated into the abdominal cavity, and will be helpful in the management of future cases of stent migration.

Endoscopy_UCTN_Code_TTT_1AR_2AI

\section{Competing interests}

The authors declare that they have no conflict of interest.

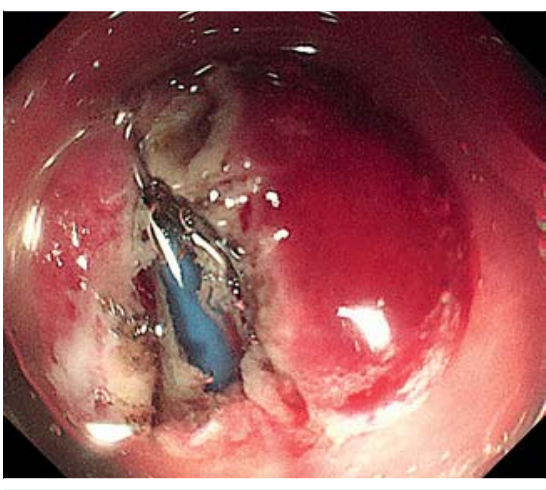

Fig. 2 A partial incision was made in the gastric wall and the migrated stent was exposed.

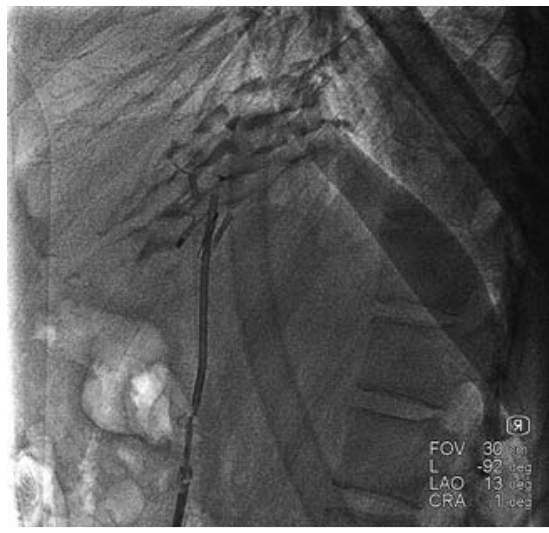

- Fig. 4 Digital radiography with contrast injection showed the stent to be unobstructed.

The authors

Longsong Li, Enqiang Linghu, Ningli Chai Department of Gastroenterology, Chinese PLA General Hospital, Beijing 100853, China

\section{Corresponding author}

\section{Ningli Chai, MD}

Department of Gastroenterology, Chinese PLA General Hospital, 28 Fuxing Road, Haidian District, Beijing 100853, China csxlily@163.com 


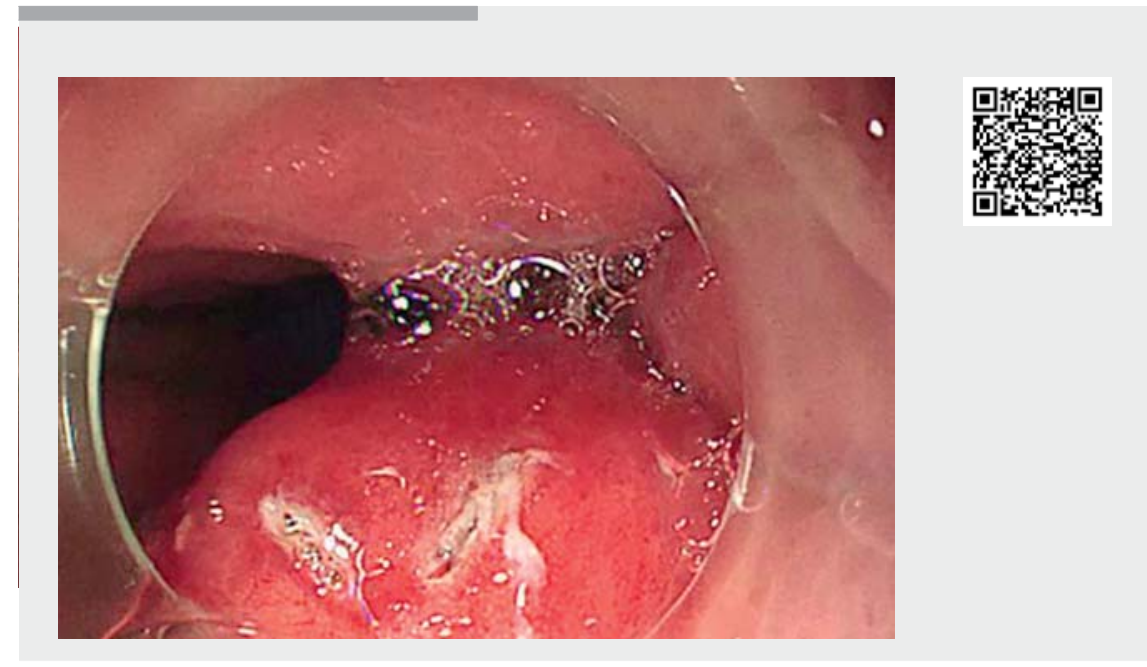

Video 1 Successful endoscopic transgastric retrieval of a plastic stent that migrated into the abdominal cavity during pancreatic fistula drainage.

\section{References}

[1] Jürgensen C, Distler M, Arlt A et al. EUSguided drainage in the management of postoperative pancreatic leaks and fistulas (with video). Gastrointest Endosc 2019; 89: 311-319

[2] Baron TH, DiMaio C], Wang AY et al. American Gastroenterological Association clinical practice update: management of pancreatic necrosis. Gastroenterology 2020; 158: $67-$ 75

[3] Law R, Grimm IS, Baron TH. Endoscopic transgastric pancreatic fistula anastomosis as treatment for a refractory pancreatic duct leak after distal pancreatectomy. Endoscopy 2016; 48: E210

\section{Bibliography}

DOI https://doi.org/10.1055/a-1103-1774

Published online: 17.2.2020

Endoscopy 2020; 52: E289-E290

(c) Georg Thieme Verlag KG

Stuttgart · New York

ISSN 0013-726X

\section{ENDOSCOPY E-VIDEOS}

https://eref.thieme.de/e-videos

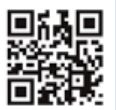

Endoscopy E-Videos is a free access online section, reporting on interesting cases and new techniques in gastroenterological endoscopy. All papers include a high quality video and all contributions are freely accessible online.

This section has its own submission website at

https://mc.manuscriptcentral.com/e-videos 